\title{
SCIENTIFIC REPORTS

\section{OPEN Tracking the Multistep Formation of Ln(III) Complexes with in situ Schiff Base Exchange Reaction and its Highly Selective Sensing of Dichloromethane}

\author{
Kai-Oiang Mo, Xiong-Feng Ma, Hai-Ling Wang, Zhong-Hong Zhu, Yan-Cheng Liu, Hua- \\ Hong Zou \& Fu-Pei Liang
}

Four complexes, namely, $\left[\mathrm{Ln}_{2}(\mathrm{L2})_{2}\left(\mathrm{NO}_{3}\right)_{4}\right] .2 \mathrm{CH}_{3} \mathrm{OH}(\mathrm{Ln}=\mathrm{Tb}(1), \mathrm{Dy}(2), \mathrm{Ho}(3), \mathrm{Er}(4)$, and $\mathrm{L} 2=(E)-2$ methoxy-6-(((pyridin-2-ylmethyl)imino)methyl)phenol), were obtained by reacting (E)-2-((3-methoxy2-oxidobenzylidene)amino)ethanesulfonate ( $\mathrm{L1}), \mathrm{Ln}\left(\mathrm{NO}_{3}\right)_{3} \cdot 6 \mathrm{H}_{2} \mathrm{O}$, and 2-aminomethylpyridine at room temperature under solvothermal conditions in methanol for $12 \mathrm{~h}$. The new Schiff base L2 was generated in situ based on the organic ligand L1 and 2-aminomethylpyridine through Schiff base exchange reaction by using lanthanide salts as inductor. A combination of crystallography and mass spectrometry was performed to track the exchange reaction, and the underlying mechanism accompanied by the complex assembly process was clearly presented. The multistep formation mechanism of the above dinuclear complex was also proposed, i.e., [L1] $\rightarrow$ Dy[L1]/[L2] $\rightarrow$ Dy[L2] $\rightarrow$ Dy[L2 $]_{2} \rightarrow$ Dy $_{2}[L 2]_{2}$. Luminescence test of 1 showed that it had extremely high selectivity to dichloromethane $\left(\mathrm{CH}_{2} \mathrm{Cl}_{2}\right)$. Therefore, we established a quick, simple, and efficient method of detecting $\mathrm{CH}_{2} \mathrm{Cl}_{2}$ that enabled strong-luminescence observation with the naked eye. Tests for small amounts of $\mathrm{CH}_{2} \mathrm{Cl}_{2}$ in water further indicated the potential of 1 as a test strip for $\mathrm{CH}_{2} \mathrm{Cl}_{2}$ fluorescence detection in water samples. Alternating-current magnetic susceptibility studies indicated the field-induced single-molecule magnet behavior of 2 .

Life originates from solution, and the complex, variable chemical reactions occurring in solution often obey laws that are difficult to predict ${ }^{1-6}$. Science has raised a major scientific problem, "How far can we push chemical self-assembly?" 5,6 . Accordingly, an important goal in chemistry is to understand and determine the precise mechanism of chemical reactions to achieve precise control of chemical reactions ${ }^{7-16}$. Complexes are usually synthesized under solvothermal conditions at certain temperatures and pressures, thereby conferring difficulty in the real-time monitoring of the reaction process and assembly mechanism ${ }^{7,8,12-16}$. Thus, reactions occurring under normal temperature and pressure conditions are beneficial to monitoring these reactions' processes and determining their mechanism. Schiff bases are the most widely used organic ligands in coordination chemistry due to their strong coordination ability, abundant coordination sites, and high coordination selectivity ${ }^{17,18}$. Schiff bases are generally stable during the formation of complexes ${ }^{17,18}$. Therefore, the identification and real-time monitoring of the in situ exchange reaction of Schiff base ligands in are difficult during complex self-assembly ${ }^{19}$. because Schiff base exchange reactions increase the number of species in a solution.

Research on process mechanisms is equally important as that on compound functions ${ }^{20,21}$. The "Holy Grail in Chemistry" emphasizes the importance of advancing research on ultrasensitive molecules for detection, which is a huge challenge ${ }^{22}$. Over the past few years, interest in finding highly selective and sensitive approaches to detecting an organic molecule with multitudes of potential health and environmental impacts has increased ${ }^{23-27}$.

State Key Laboratory for Chemistry and Molecular Engineering of Medicinal Resources, School of Chemistry \& Pharmacy of Guangxi Normal University, Guilin, 541004, P.R. China. Kai-Qiang Mo, Xiong-Feng Ma and Hai-Ling Wang contributed equally. Correspondence and requests for materials should be addressed to Z.-H.Z. (email: 18317725515@163.com)or H.-H.Z. (email: gxnuchem@foxmail.com)or F.-P.L. (email: fliangoffice@yahoo.com) 
a)

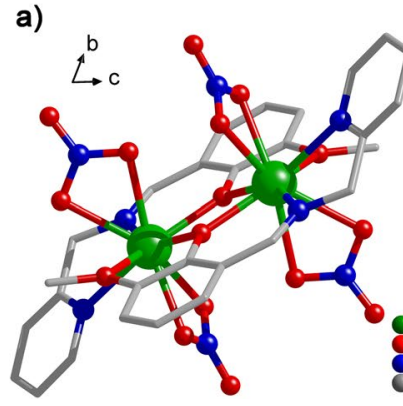

b) $\rightarrow a$

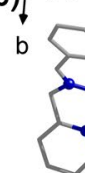

8

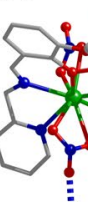

列

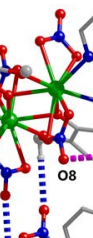

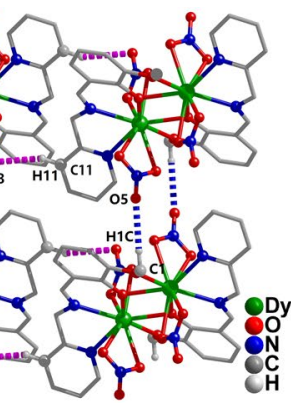

c)

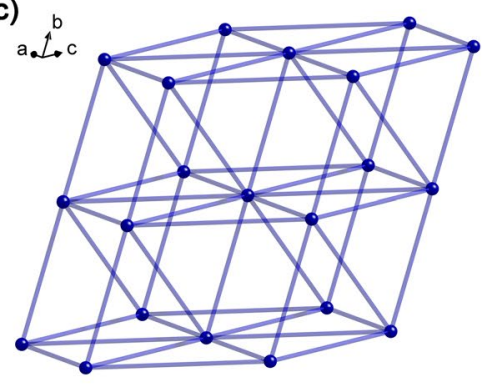

Figure 1. (a) Crystal structure for $\operatorname{Ln} 2$ with most $H$ atoms omitted for clarity. (b) Structure of $\operatorname{Ln} 2$ showing the supramolecular interactions: same type $\mathrm{C} 1-\mathrm{H} 1 \mathrm{C} \cdots \mathrm{O} 5$ (blue dotted line) and C11 - H11 ‥O8 (pink dotted line) hydrogen bonds. (c) Connecting modes of clusters through hydrogen bonds in Ln2 (Ln = Dy, Tb, Ho, Er).

Among such organic molecules is dichloromethane $\left(\mathrm{CH}_{2} \mathrm{Cl}_{2}\right)$, which is one of the most commonly used organic solvents in chemical production, film production, and pharmaceutical fields; however, its large emissions lead to water and air pollution ${ }^{28}$. The detection of $\mathrm{CH}_{2} \mathrm{Cl}_{2}$ still relies on gas chromatography, a quasi-quantitative detection technology that requires considerable time, labor, and cost. Therefore, for certain specific environments and the rational allocation of resources, developing a real-time, rapid detection method for $\mathrm{CH}_{2} \mathrm{Cl}_{2}$ is urgent. The design, synthesis, and development of selective and sensitive organic molecule sensors are research hotspots s $^{23-27}$. although the rapid detection of many organic molecules such as tetrahydrofuran (THF) ${ }^{27}$. and acetonitrile ${ }^{26}$. has been achieved. However, methods with high selectivity and fast response to $\mathrm{CH}_{2} \mathrm{Cl}_{2}$ remain necessary to establish.

Herein, we achieved an in situ Schiff base exchange reaction between (E)-2-((3-methoxy-2-oxidobenzylidene) amino)ethanesulfonate (L1) and 2-aminomethylpyridine induced by $\operatorname{Ln}(\mathrm{III})$ ions at room temperature to obtain $\left[\mathrm{Ln}_{2}(\mathbf{L 2})_{2}\left(\mathrm{NO}_{3}\right)_{4}\right] \cdot 2 \mathrm{CH}_{3} \mathrm{OH}(\mathrm{Ln}=\mathrm{Tb}(\mathbf{1})$, Dy (2), Ho (3), and Er (4); L2 = (E)-2-methoxy-6-(((pyridin2-ylmethyl)imino)methyl)phenol). We used a combination of crystallography and electrospray ionization mass spectrometry (ESI-MS) to track the multistep assembly process of the above-described dinuclear complexes and proposed its assembly mechanism. The Schiff base exchange mechanism accompanying the complex assembly process was tracked and proposed (Table S1). This method can serve as an invaluable reference for mechanistic research (Tables S1-S2). Complexes 1 and 2, dissolved in $N, N$-dimethylformamide (DMF), showed $\pi-\pi^{*}$ level transitions between ligands, as well as energy-level transitions from metal-ion-to-ligand charge transfer (MLCT). When 1 was dissolved in a different solvent to test its luminescence, it showed strong fluorescence in $\mathrm{CH}_{2} \mathrm{Cl}_{2}$ and weak fluorescence in other solvents. When 1 was dissolved and dispersed in different organic solvents under a $\mathrm{UV}$ lamp, only $\mathrm{CH}_{2} \mathrm{Cl}_{2}$ solution showed strong luminescence. Thus, the method was a rapid, easy, and effective way to detect $\mathrm{CH}_{2} \mathrm{Cl}_{2}$.

\section{Results and Discussion}

Single-crystal X-ray diffraction studies. X-ray diffraction results suggested that $\mathbf{1}, 2,3$, and 4 crystallized in the triclinic crystal system with the $P$ - 1 space group (Table S3), in which the nine-coordinated $\left(\mathrm{N}_{2} \mathrm{O}_{7}\right) \operatorname{Ln}(\mathrm{III})$ cores were surrounded by two $\mathrm{N}$ atoms, two $\mu_{2}-\mathrm{O}^{-}$ions, one $\mathrm{O}$ atom from two L2, and two bidentate chelating nitrate anions (Fig. 1a). The intracluster $\mathrm{Ln}$ (III) ions were bridged by two phenoxo oxygen atoms from L2 ligands. The bond length distances of Ln-O varied from 2.308(2) to 2.501(3) $\AA$ for 1, from 2.298(2) to 2.488(3) for 2, from 2.292(2) to 2.478(3) Å for 3, and from 2.288(3) to 2.494(4) $\AA$ for 4. The average Ln-O bond lengths were $2.436,2.423,2.411$, and $2.407 \AA$ for $\mathbf{1}, 2,3$, and 4 , respectively. The Ln-N bond distances ranged within

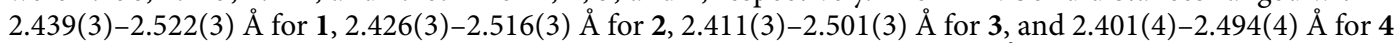
(Table S4). The intracluster Ln …Ln distances were 3.741, 3.730, 3.719, and 3.713 $\AA$ for 1, 2, 3, and 4, respectively. By studying the weak interactions among the Ln2 molecules, only two of the same type of weak interaction, i.e., $\mathrm{C}-\mathrm{H}$... O hydrogen bonding, were found (Fig. 1b); however, for all compounds, a slight difference in distance was observed (Table S5). The connecting modes of the clusters through hydrogen bonds and the above-mentioned supramolecular weak-action distances were all within a logical range. Thus, they can be considered as a formation of 10-connected $\boldsymbol{f} \boldsymbol{c} \boldsymbol{u}$ net (Fig. 1c) with distances of 9.976-12.590 $\mathrm{A}$ for 1, 9.972-12.572 $\mathrm{A}$ for 2, 9.947-12.531 $\mathrm{f}$ for 3, and 9.944-12.527 $\AA$ for $\mathbf{4}$ between the centers of the Ln2 dimer. By using SHAPE, the calculated results suggested that the geometry of the nine-coordinated $\operatorname{Ln}(\mathrm{III})$ was a muffin for $\mathbf{L n} 2$ (Tables S6-S9). The TGA curves of the four compounds are shown in Fig. S1. The phase purities of 1, 2, 3, and 4 were determined from their powder $\mathrm{X}$-ray diffraction patterns (Fig. S2).

To study the stability of the dinuclear complexes in solution, we performed ESI-MS tests. For the mass spectra of $\mathbf{1}, \mathbf{2}, \mathbf{3}$, and 4 , their peak location and frame peaks were similar, so only the details of $\mathbf{2}$ were provided in the ensuing discussion. According to the correlation between the solid and liquid structures, at $\mathrm{m} / z=993.00$ (the main frame peak of the structure), the molecular formula $\left[\mathrm{Dy}_{2}(\mathbf{L 2})_{2}\left(\mathrm{NO}_{3}\right)_{3}\right]^{+}($calc. 993.01$)$ was obtained by analysis and fitting. However, its peak strength was $<0.1$, indicating that 2 was unstable based on the mass spectrum in solution. A similar peak appeared at $m / z=1173.12$. $\left[\mathrm{Dy}_{2}(\mathbf{L 2})_{3}\left(\mathrm{NO}_{3}\right)_{2}\right]^{+}($calc. 1173.12) can be obtained by fitting, indicating that with a [L2 $]^{-}$ligand instead of a $\mathrm{NO}_{3}{ }^{-}$anion, its strength was lower. The highest intensity peak appeared at $m / z=312.09$, and the bivalent peak of $\left[\mathrm{Dy}(\mathbf{L 2})(\mathrm{DMF})_{3}\right]^{2+}$ (calc.312.09) was obtained by fitting. Similar fragment peaks appeared at $m / z=275.56$ and 348.62, and the molecular fragments showed divalence, which differed from the number of DMF. This finding indicated that $\mathbf{2}$ was broken into the half-structure of DyL2 


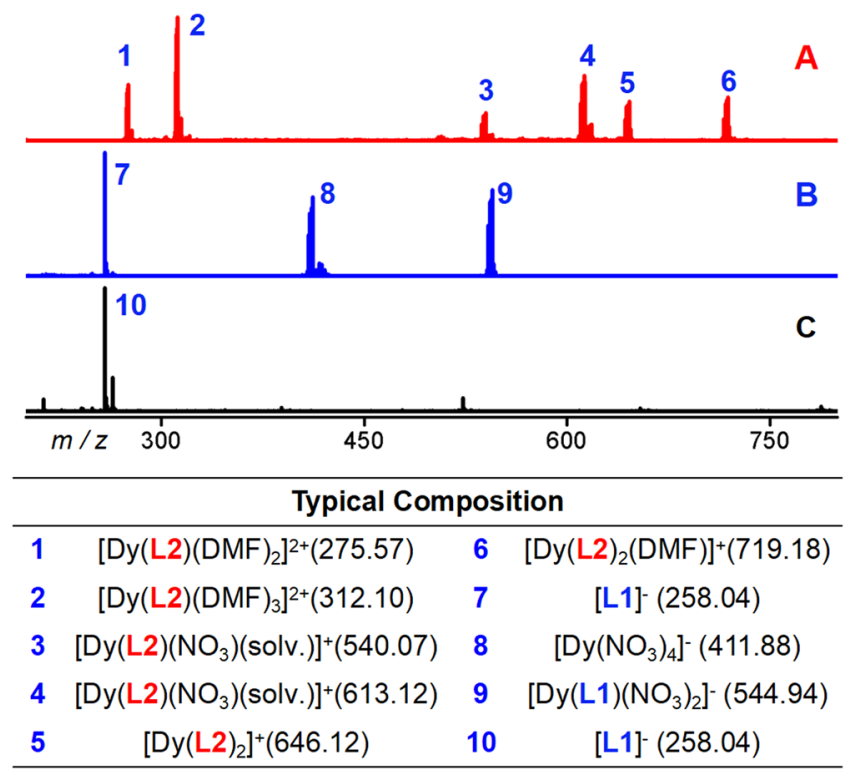

Figure 2. Top: (A) ESI-MS spectrum of crystal 2 in positive mode. (B) $\mathbf{L} 1+\mathrm{Dy}\left(\mathrm{NO}_{3}\right)_{3} \cdot 6 \mathrm{H}_{2} \mathrm{O}$ was reacted in methanol at room temperature for $24 \mathrm{~h}$ (no added 2 -aminomethylpyridine; negative mode). (C) $\mathrm{L1}+2$-aminomethylpyridine was reacted in methanol at room temperature for $24 \mathrm{~h}$ (no added Dy $\left(\mathrm{NO}_{3}\right)_{3} \cdot 6 \mathrm{H}_{2} \mathrm{O}$; negative mode). Bottom: major species assigned in the ESI-MS.

a)

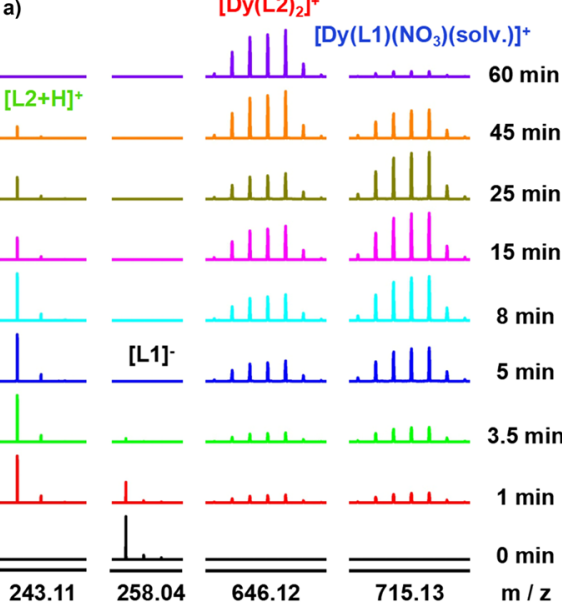

b)
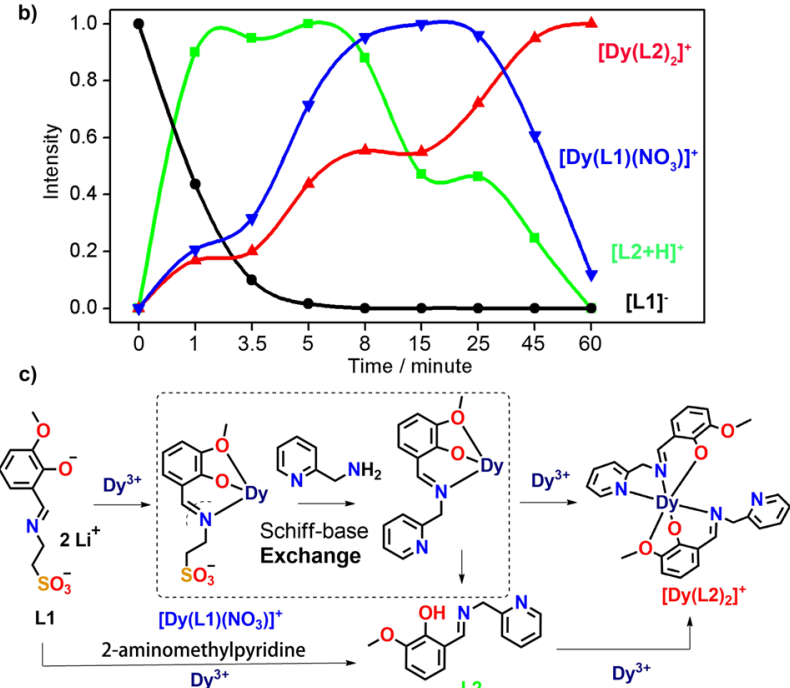

Figure 3. (a) Time-dependent ESI-MS tracks the formation of 2 and the Schiff base exchange process. (b) The tendency of fragments appearing during the reaction to change over time. (c) A 2 multistep assembly mechanism comprising a Schiff base exchange reaction (solv. $\left.=(\mathrm{DMF})_{2}\left(\mathrm{CH}_{3} \mathrm{OH}\right)\left(\mathrm{H}_{2} \mathrm{O}\right)_{3}\right) . \mathrm{NO}_{3}{ }^{-}$ions are omitted for clarity.

under mass-spectrometry condition, and DMF replaced the position of the $\mathrm{NO}_{3}{ }^{-}$anion and showed a +2 valence. Moreover, at $m / z=540.06$ and 613.12, $\left[\mathrm{Dy}(\mathbf{L 2})\left(\mathrm{NO}_{3}\right)(\mathrm{DMF})\right]^{+}\left(\right.$calc.540.06) and $\left[\mathrm{Dy}(\mathbf{L} 2)\left(\mathrm{NO}_{3}\right)(\mathrm{DMF})_{2}\right]^{+}$ (calc.613.12) were obtained by fitting, and their intensities were 0.221 and 0.526 , respectively. At $m / z=646.12$ and 719.17, these miframe changed, the molecular formulas $\left[\mathrm{Dy}(\mathbf{L 2})_{2}\right]^{+}\left(\right.$calc.646.12) and $\left[\mathrm{Dy}(\mathbf{L 2})_{2}(\mathrm{DMF})\right]^{+}$ (calc.719.17) were obtained by fitting, and a [L2 $]^{-}$ligand was found to replace a $\mathrm{NO}_{3}{ }^{-}$anion (strength $>0.3$ ). Overall, under the ESI-MS condition, the above dinuclear complexes were more prone to homolysis to produce DyL2 semistructural fragments, and only a small amount of dinuclear structure lost one Dy(III) ion to produce Dy(L2) ${ }_{2}$ fragments (Fig. 2). Although the binuclear framework of 1, 2, 3, and 4 was unstable under ESI-MS conditions, L2 in the above complexes was always stable (Figs S3-S13, Tables S10 and S11). The ESI-MS measurements for control experiments were performed in negative mode (Fig. 2) but those for the Schiff-base exchange reaction were conducted in positive mode (Fig. 3a); the other positive or negative mode are shown in the Supporting 

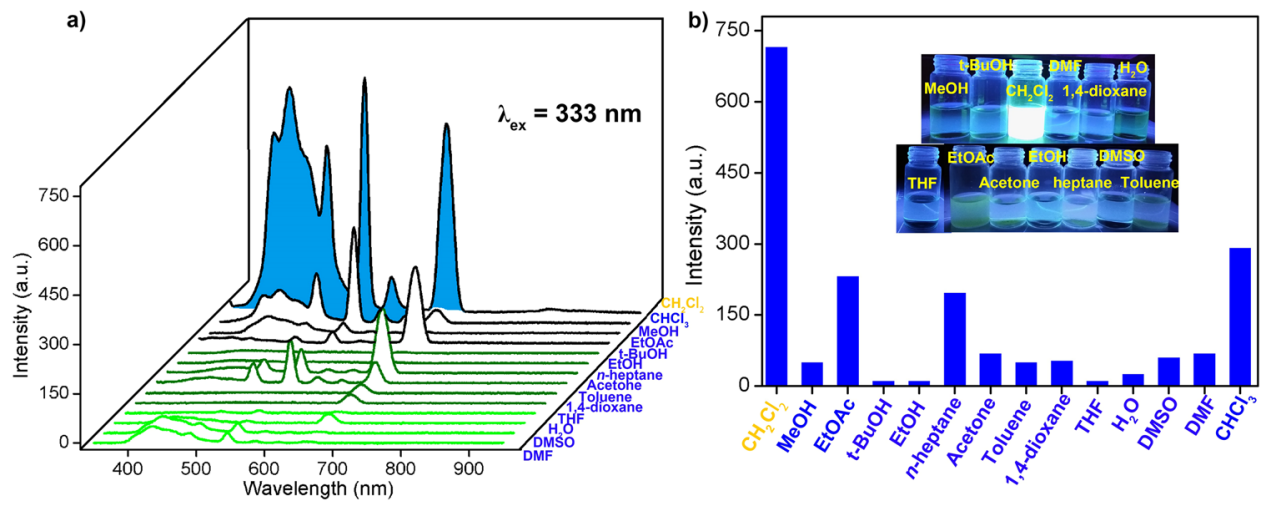

Figure 4. (a) Emission spectra of 1 dispersed in different organic molecules ( $5 \mathrm{mg} / 10 \mathrm{~mL}$; excited at $333 \mathrm{~nm}$ ). (b) Luminescence intensity of $\mathbf{1}$ with different organic molecules. The inset shows the corresponding photographs under UV-light irradiation at $365 \mathrm{~nm}$.

Information (Fig. S3,a,c). We also attempted to dissolve crystal 2 in methanol, and high-intensity peaks for the $\left[\mathrm{Dy}(\mathbf{L} 2)_{2}\right.$ (solv.)] molecular fragment were found (Fig. S4,b).

Interestingly, the $\mathbf{L} \mathbf{1}$ we used was not found in the structure, but 2-aminomethylpyridine replaced the position of taurine in situ with $o$-vanillin to form a Schiff base ligand. To investigate how 2-aminomethylpyridine replaced the 2-aminoethanesulfonic acid in $\mathbf{L} 1$, we performed a control experiment. $\mathbf{~} \mathbf{1}+\mathrm{Dy}\left(\mathrm{NO}_{3}\right)_{3} \cdot 6 \mathrm{H}_{2} \mathrm{O}$ (without added 2 -aminomethylpyridine) was reacted in methanol at room temperature for $24 \mathrm{~h}$. The main fragment obtained

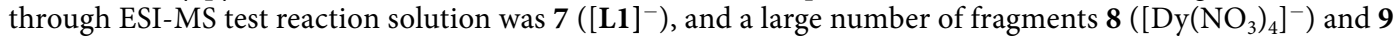
$\left(\left[\mathrm{Dy}(\mathbf{L} \mathbf{1})\left(\mathrm{NO}_{3}\right)_{2}\right]^{-}\right)$were also present. $\mathbf{L 1}+2$-aminomethylpyridine (without added $\mathrm{Dy}\left(\mathrm{NO}_{3}\right)_{3} \cdot 6 \mathrm{H}_{2} \mathrm{O}$ ) was reacted in methanol at room temperature for $24 \mathrm{~h}$, and the main fragment obtained with ESI-MS test reaction solution was $10\left(7,[\mathbf{L 1}]^{-}\right)$(Figs 2 and S3). The above control experiments showed that the Schiff base replacement reaction did not occur without $\mathrm{Ln}$ (III) induction, i.e., 2-aminoethanesulfonic acid was first coordinated with Dy(III) ions in solution and then replaced with 2 -aminomethylpyridine. Thus, the time-dependent tracking of the replacement process revealing its mechanism of replacement self-assembly was interesting. Notably, time-dependent assembly occurred at room temperature, which benefited slowing down the reaction rate and observing the process. It was followed by a 60 min time gradient. When $\mathbf{L 1}, 2$-aminomethylpyridine, and $\mathrm{Dy}\left(\mathrm{NO}_{3}\right)_{3} \cdot 6 \mathrm{H}_{2} \mathrm{O}$ were added, no reaction occurred. About $1 \mathrm{~min}$ later, substitution occurred rapidly and the ligand after in situ replacement appeared at $m / z=243.11$. The molecular formula was $[(\mathbf{L 2})+\mathrm{H}]^{+}$(calc. 243.11) by fitting, but $\mathbf{L} \mathbf{1}$ ligand was reduced to 0.437 until it almost disappeared $3.5 \mathrm{~min}$ later. Moreover, with increased reaction time, the peak intensity of the $\mathbf{L} 2$ fragment gradually decreased to $60 \mathrm{~min}$. Two weak peaks appeared at $\mathrm{m} / z=715.13$ and 646.12 , and $\left[\mathrm{Dy}(\mathbf{L 1})\left(\mathrm{NO}_{3}\right)(\text { solv. })\right]^{+}$(calc. 715.13$)$ and $\left[\mathrm{Dy}(\mathbf{L 2})_{2}\right]^{+}($calc.646.12) was obtained by fitting. However, with increased reaction time, the peak intensities of the two groups gradually increased. Figure 3 shows that the frame fragment of 646.12 obviously did not grow rapidly with 715.13 . After $8 \mathrm{~min}$, $\left[\mathrm{Dy}(\mathrm{L1})\left(\mathrm{NO}_{3}\right)(\text { solv. })\right]^{+}$gradually increased to the highest. However, after $45 \mathrm{~min}$, the peak intensity of the molecular fragment of $\left[\mathrm{Dy}(\mathbf{L} 2)_{2}\right]^{+}$gradually increased to the highest until $60 \mathrm{~min}$ when the $\left[\mathrm{Dy}(\mathbf{L 1})\left(\mathrm{NO}_{3}\right)(\text { solv. })\right]^{+}$framework fragment disappeared. Thus, driven by $\mathrm{Dy}\left(\mathrm{NO}_{3}\right)_{3} \cdot 6 \mathrm{H}_{2} \mathrm{O}, 2$-aminomethylpyridine gradually replaced taurine in $\mathbf{L} \mathbf{1}$ with increased time and then assembled into the $\mathbf{2}$ frame (Figs S14, S15, and Table S12). In summary, through ESI-MS analysis, we speculated that the possible formation mechanism of $\mathbf{2}$ was $[\mathbf{L} \mathbf{1}] \rightarrow \mathrm{Dy}[\mathbf{L} \mathbf{1}] /[\mathbf{L} 2] \rightarrow \mathrm{Dy}[\mathbf{L} \mathbf{2}] \rightarrow \mathrm{Dy}[\mathbf{L} 2]_{2} \rightarrow \mathrm{Dy}_{2}[\mathbf{L}$ $2]_{2}$. The exchange of Schiff base occurred during the reaction in Dy[L1] $\rightarrow \mathrm{Dy}[\mathbf{L 2}]$. In this work, the Schiff base replacement reaction, which accompanied the assembly of the lanthanide complex, was studied through a combination of crystallography and mass spectrometry. Moreover, the most suitable time and stage of Schiff base replacement were clearly explained.

Dichloromethane is the most common organic solvent and is widely used in organic synthesis. Its rapid and easy detection is a huge challenge. Based on the above luminescence studies (Figs S16 and 17), we used $\mathbf{1}$ as a fluorescent probe to examine its potential for sensing organic molecules. The as-obtained products ( $5 \mathrm{mg})$ were ground and dissolved in $10 \mathrm{~mL}$ of various organic solvents $\left(\mathrm{CHCl}_{3}, \mathrm{MeOH}, \mathrm{t}-\mathrm{BuOH}, \mathrm{CH}_{2} \mathrm{Cl}_{2}, \mathrm{DMF}, 1\right.$,4-dioxane, $\mathrm{H}_{2} \mathrm{O}$, THF, EtOAc, acetone, EtOH, $n$-heptane, DMSO, and toluene). When we excited $\mathbf{1}$ in different organic solvents at an excitation wavelength of $333 \mathrm{~nm}$, we found that the emission peak of 1 dissolved in $\mathrm{CH}_{2} \mathrm{Cl}_{2}$ was remarkably higher than those of the other organic solvents. When 1 was dissolved and dispersed in $\mathrm{CH}_{2} \mathrm{Cl}_{2}$, it showed a strong, broad emission peak at $435 \mathrm{~nm}$ and strong emission peaks at 545 and $667 \mathrm{~nm}$. Weak emission peaks were also observed at 490,585, and $620 \mathrm{~nm}$. When 1 was dissolved and dispersed in $\mathrm{CHCl}_{3}$, although it exhibited the same emission peak position as $\mathrm{CH}_{2} \mathrm{Cl}_{2}$, the luminescence intensity was weak. These emission peaks can be assigned to the $\pi-\pi *$ level transition of the organic ligand $\mathbf{L 2}$, and the energy-level transition of the organic ligand (organic molecule) to the $\mathrm{Tb}$ (III) ion (Fig. 4a). To resolve $\mathrm{CH}_{2} \mathrm{Cl}_{2}$ quickly and easily, we placed a solution containing different organic molecules of 1 in a portable UV lamp at $365 \mathrm{~nm}$. The fluorescence in the $\mathrm{CH}_{2} \mathrm{Cl}_{2}$ solution was clearly visible to the naked eye, whereas the emission in other organic solvents was weak. Therefore, the $\mathrm{CH}_{2} \mathrm{Cl}_{2}$ solution was quickly and easily distinguished (Fig. $4 \mathrm{~b}$ ).

We subsequently performed a luminescence titration experiment to examine the probe sensitivity. A certain amount of $\mathrm{CH}_{2} \mathrm{Cl}_{2}$ was separately added to the DMF solution containing 1 to test its fluorescence emission 

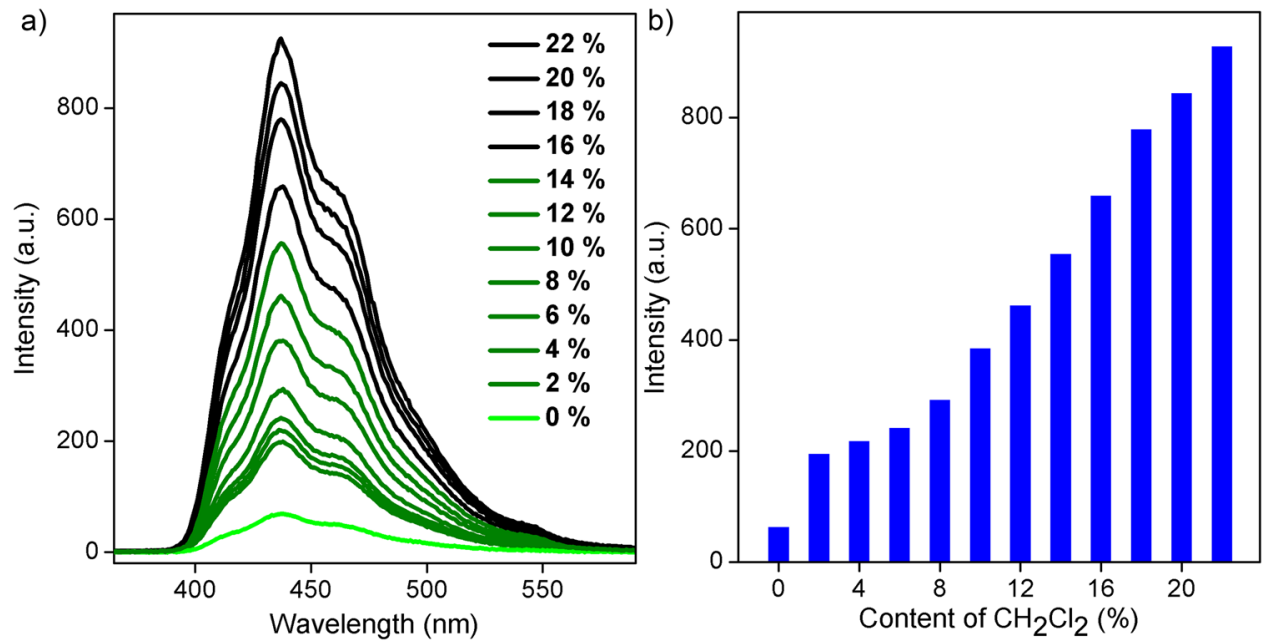

Figure 5. (a) Luminescence spectra of 1 dispersed in DMF with increased $\mathrm{CH}_{2} \mathrm{Cl}_{2}$ concentration $\left(\mathrm{CH}_{2} \mathrm{Cl}_{2} /\right.$ DMF). (b) Changes in fluorescence intensity with increased $\mathrm{CH}_{2} \mathrm{Cl}_{2}$ concentration in DMF solution.

(Fig. 5a). Without $\mathrm{CH}_{2} \mathrm{Cl}_{2}$, the solution showed a weak luminescence with a strength of only 68 , whereas the addition of $2 \% \mathrm{CH}_{2} \mathrm{Cl}_{2}$ solution led to a remarkable increase in luminescence intensity to 198 . With gradually increased $\mathrm{CH}_{2} \mathrm{Cl}_{2}$ content, the solution fluorescence gradually increased. With increased $\mathrm{CH}_{2} \mathrm{Cl}_{2}$ content to $22 \%$, the luminous intensity of the solution increased to 928 (Fig. 5b). To verify the detection effect of 1 fluorescent probe on $\mathrm{CH}_{2} \mathrm{Cl}_{2}$ in sewage, we mixed a certain amount of $\mathrm{CH}_{2} \mathrm{Cl}_{2}$ and $\mathrm{H}_{2} \mathrm{O}$, and the fluorescence increased rapidly with increased $\mathrm{CH}_{2} \mathrm{Cl}_{2}$ content in water (Fig. S18).

Magnetic properties. DC magnetic susceptibilitiy studies of 1, 2, 3, and 4 were conducted in a 1000 Oe field from 300 to $2 \mathrm{~K}$ (Fig. S19). At room temperature, the $\chi_{\mathrm{M}} T$ values of $23.75,28.51,28.22$, and $23.13 \mathrm{~cm}^{3} \mathrm{~K} \mathrm{~mol}^{-1}$ were consistent with the expected values for two isolated $\mathrm{Tb}(\mathrm{III}), \mathrm{Dy}(\mathrm{III}), \mathrm{Ho}(\mathrm{III})$, and $\mathrm{Er}(\mathrm{III})$ ions, respectively. These $\chi_{\mathrm{M}} T$ values gradually decreased with decreased temperature until $50 \mathrm{~K}$ before decreasing rapidly to reach $9.48,8.92,7.61$ and $9.13 \mathrm{~cm}^{3} \mathrm{~K} \mathrm{~mol}^{-1}$ at $2 \mathrm{~K}$, respectively. The decreases may be attributed to the thermal depopulation of the $\operatorname{Ln}$ (III) Stark sublevels ${ }^{29-33}$. The maximum values of magnetization for $1,2,3$, and 4 were not saturated at $5 \mathrm{~T}$ and $2 \mathrm{~K}$ (Fig. S20). The saturation was not reached because the orbital contribution to the magnetic moment was very important and led to strong magnetic anisotropy. Alternating current (AC) magnetic susceptibilities suggest that only 2 exhibited weak frequency-dependent behavior in zero DC field (Fig. S21). Usually, a small magnetic field is efficient to observe the slow relaxation of magnetization and suppress the possible quantum tunneling effect of magnetization. Only a more obvious frequency-dependent behavior at 2000 Oe DC field, i.e., the effect of dc field on magnetic relaxation, was observed ${ }^{34,35}$. The Cole-Cole plots fitted by Debye model are shown in Fig. S22. The fitting parameters $\tau$ and $\alpha$ are listed in Tables S13. The parameter $\alpha$ ranged within 0.240.34 , which showed the relatively moderate distribution of each relaxation time. Afterwards, we analyzed the temperature-dependent relaxation time by Arrhenius law $\left(\tau=\tau_{0} \exp \left(U_{\text {eff }} / k_{\mathrm{B}} T\right)\right)$, and the energy barrier and relaxation time were found to be $U_{\text {eff } 1}=17.9 \mathrm{~K}$ and $\tau_{1}=3.5 \times 10^{-7} \mathrm{~s}$ under a 2000 Oe dc field (Fig. S22 and Table S13). An $S$-shaped magnetization hysteresis for 2 (Fig. S23) was observed with a steep rise at the crossing field $H=5 \mathrm{~T}$.

\section{Conclusions}

A rare in situ Schiff base exchange reaction was found and its process was examined by crystallography and mass spectrometry. The reaction was accompanied by a multistep assembly of lanthanide metal ions to afford a series of lanthanide-metal-complex fragment. The exchange of the Schiff base occurred after the original ligand $\mathbf{L} \mathbf{1}$ was coordinated and then multistep assembly occurred to give the product, i.e., $[\mathbf{L} \mathbf{1}] \rightarrow \mathrm{Dy}[\mathbf{L} \mathbf{1}] /[\mathbf{L} \mathbf{2}] \rightarrow \mathrm{Dy}$ $[\mathbf{L 2}] \rightarrow \mathrm{Dy}[\mathbf{L} 2]_{2} \rightarrow \mathrm{Dy}_{2}[\mathbf{L} 2]_{2}$. Furthermore, the quick, easy, and selective identification of $\mathrm{CH}_{2} \mathrm{Cl}_{2}$ was realized using 1 as fluorescence probe. To the best of our knowledge, this study is the first to explore the quick and easy fluorescence sensing of $\mathrm{CH}_{2} \mathrm{Cl}_{2}$. This work shows the great potential of lanthanide metal ions for the in situ Schiff base exchange and as a fluorescence probe. Our research method described an in situ reaction during complex self-assembly, which may provide new insights into the quick and easy detection of $\mathrm{CH}_{2} \mathrm{Cl}_{2}$ and thus the foundation for the discovery of highly effective and convenient detection methods.

\section{Experimental Section}

Materials and measurements. All reagents were obtained from commercial sources and used without further purification. Elemental $(\mathrm{C}, \mathrm{H}$, and $\mathrm{N}$ ) analysis was conducted on an Elementar Micro cube elemental analyzer. Thermal analysis was performed in $\mathrm{N}_{2}$ at a heating rate of $5^{\circ} \mathrm{C} / \mathrm{min}$ using Labsys Evo TG-DTG/DSC. IR spectra with $\mathrm{KBr}$ pellet were recorded on PE Spectrum Two FT/IR spectrometer $\left(400-4000 \mathrm{~cm}^{-1}\right)$. PXRD measurements were recorded on a Rigaku D/max-IIIA diffractometer. Magnetic susceptibility was measured with a MPMS SQUID-XL magnetometer equipped with $5 \mathrm{~T}$ magnet within the temperature range of 2-300 K. Diamagnetic corrections were estimated using Pascal's constants. AC susceptibility was measured and data were 
collected at increasing temperatures from $2 \mathrm{~K}$ to $10 \mathrm{~K}$ within frequencies ranging from $1 \mathrm{~Hz}$ to $1000 \mathrm{~Hz}$ and a drive frequency of $2.5 \mathrm{Oe}$.

Single-crystal X-ray crystallography. The diffraction data of all complexes were obtained on a Bruker SMART CCD diffractometer (Mo K $\alpha$ radiation and $\lambda=0.71073 \AA$ ) in $\Phi$ and $\omega$ scan modes. All structures were solved by direct methods followed by difference Fourier syntheses and then refined by full-matrix least-square techniques on $F^{2}$ using SHELXL ${ }^{36}$. All other non-hydrogen atoms were refined with anisotropic thermal parameters. Hydrogen atoms were placed in the calculated position and refined in the isotropic direction using a riding model. Table S1 summarizes X-ray crystallographic data and refinement details of the complexes. Complete details can be found in the CIF files provided in the Supporting Information. The CCDC reference numbers are 1879618 for 1,1879615 for 2, 1879617 for 3, and 1879616 for 4 .

High-resolution ESI-MS test. High-resolution ESI-MS were performed at the capillary temperature of $275^{\circ} \mathrm{C}$, and the solution was injected at a rate of $0.3 \mathrm{~mL} / \mathrm{h}$. The ESI-MS used for the measurements was a ThermoExactive, and data were collected in positive and negative ion modes. The spectrometer was previously calibrated with the standard tune mix to give a precision of $c a .2 \mathrm{ppm}$ within the range of $200-2500 \mathrm{~m} / z$. The capillary voltage was $50 \mathrm{~V}$, the tube lens voltage was $150 \mathrm{~V}$, and the skimmer voltage was $25 \mathrm{~V}$. The in-source energy was set within the range of $0-100 \mathrm{eV}$ with a gas flow rate at $10 \%$ of the maximum.

Synthesis of complexes $1,2,3$, and 4. The mixture of $\left[\mathrm{Li}_{2} \mathrm{Ll}\right]$ ligand $(0.5 \mathrm{mmol}), \operatorname{Ln}\left(\mathrm{NO}_{3}\right)_{3} \cdot 6 \mathrm{H}_{2} \mathrm{O}$ $(0.5 \mathrm{mmol}), 2$-aminomethylpyridine $(2 \mathrm{mmol})$, and $10 \mathrm{~mL} \mathrm{CH}_{3} \mathrm{OH}$ were stirred for $2 \mathrm{~h}$ in $25 \mathrm{~mL}$ Bunsen beaker and then volatilized at room temperature for $12 \mathrm{~h}$ to obtain yellow crystals. 1: yield: $75 \%$ (based on $\left.\mathrm{Tb}\left(\mathrm{NO}_{3}\right)_{3} \cdot 6 \mathrm{H}_{2} \mathrm{O}\right)$. IR data for $\left(\mathrm{KBr}, \mathrm{cm}^{-1}\right): 3411(\mathrm{~m}), 1645(\mathrm{~m}), 1500(\mathrm{~s}), 1430(\mathrm{~s}), 1384(\mathrm{~s}), 1272(\mathrm{~s}), 1038(\mathrm{~m}), 893$ $(s), 813(m), 742(s), 645(w), 523(m), 492(s), 434(w)$. Elemental analyses calc $(\%)$ for $\left[\mathrm{Tb}_{2}\left(\mathrm{~L} 2_{2}\right)_{2}\left(\mathrm{NO}_{3}\right)_{4}\right] \cdot 2 \mathrm{CH}_{3} \mathrm{OH}$ : C 32.56, H 2.55, N 10.13; Found: C 32.39, H 2.67, N 10.06. 2: yield: $72 \%$ (based on Dy $\left.\left(\mathrm{NO}_{3}\right)_{3} \cdot 6 \mathrm{H}_{2} \mathrm{O}\right)$. IR data $(\mathrm{KBr}$, $\left.\mathrm{cm}^{-1}\right): 3410(\mathrm{~m}), 1644(\mathrm{~m}), 1509(\mathrm{~s}), 1461(\mathrm{~s}), 1384(\mathrm{~s}), 1272(\mathrm{~s}), 1037(\mathrm{~m}), 892(\mathrm{~s}), 813(\mathrm{~m}), 745(\mathrm{~s}), 642(\mathrm{w})$, $522(m), 495(s), 430(w)$. Elemental analyses calc $(\%)$ for $\left[\mathrm{Dy}_{2}(\mathbf{L} 2)_{2}\left(\mathrm{NO}_{3}\right)_{4}\right] \cdot 2 \mathrm{CH}_{3} \mathrm{OH}: \mathrm{C} 32.36, \mathrm{H} 2.53, \mathrm{~N} 10.06$; Found: C 31.21, H 2.69, N 10.01. 3: yield: 77\% (based on $\left.\mathrm{Ho}\left(\mathrm{NO}_{3}\right)_{3} \cdot 6 \mathrm{H}_{2} \mathrm{O}\right)$. IR data $\left(\mathrm{KBr}, \mathrm{cm}^{-1}\right): 3405(m), 1646$ $(\mathrm{m}), 1501(\mathrm{~s}), 1431(\mathrm{~s}), 1384(\mathrm{~s}), 1273(\mathrm{~s}), 1039(\mathrm{~m}), 893(\mathrm{~s}), 813(\mathrm{~m}), 743(\mathrm{~s}), 641(\mathrm{w}), 525(\mathrm{~m}), 492(\mathrm{~s}), 438(w)$. Elemental analyses calc (\%) for $\left[\mathrm{Ho}_{2}(\mathrm{L2})_{2}\left(\mathrm{NO}_{3}\right)_{4}\right] \cdot 2 \mathrm{CH}_{3} \mathrm{OH}$ : C 32.22, $\mathrm{H} 2.52, \mathrm{~N} 10.02$; Found: C 32.05, $\mathrm{H} 2.63, \mathrm{~N}$ 9.98. 4:yield: $71 \%$ (based on $\left.\operatorname{Er}\left(\mathrm{NO}_{3}\right)_{3} \cdot 6 \mathrm{H}_{2} \mathrm{O}\right)$. IR data $\left(\mathrm{KBr}, \mathrm{cm}^{-1}\right): 3400(\mathrm{~m}), 1646(\mathrm{~m}), 1503(\mathrm{~s}), 1431(\mathrm{~s}), 1384$ $(\mathrm{s}), 1276(\mathrm{~s}), 1039(\mathrm{~m}), 898(\mathrm{~s}), 815(\mathrm{~m}), 742(\mathrm{~s}), 643(\mathrm{w}), 522(\mathrm{~m}), 490(\mathrm{~s}), 434(\mathrm{w})$. Elemental analyses calc $(\%)$ for $\left[\mathrm{Er}_{2}(\mathbf{L} 2)_{2}\left(\mathrm{NO}_{3}\right)_{4}\right] \cdot 2 \mathrm{CH}_{3} \mathrm{OH}: \mathrm{C} 32.08, \mathrm{H} 2.51, \mathrm{~N}$ 9.98; Found: C 31.99, H 2.58, N 9.93.

Synthesis of ligand HL2. O-vanillin ( $1 \mathrm{mmol}$ ) was dissolved in $25 \mathrm{~mL}$ of anhydrous methanol and then 2 -aminomethylpyridine $(1 \mathrm{mmol})$ was added. The mixture was stirred overnight and methanol was evaporated to give a yellow solid. Yield: 84\% (based on o-vanillin). ([HL2+H] $]^{+}$Expt.m/z=243.11, Calc. $m / z=243.10$.

\section{References}

1. Nevado, C. \& De Haro, T. New Strateg. Chem. Synth. Catal. (Wiley-VCH Verlag GmbH \& Co. KGaA, Weinheim, Germany, 2012).

2. Krishnamurthy, R. Giving Rise to Life: Transition from Prebiotic Chemistry to Protobiology. Acc. Chem. Res. 50, 455-459 (2017).

3. Sun, Q. F., Sato, S. \& Fujita, M. An $\mathrm{M}_{18} \mathrm{~L}_{24}$ stellated cuboctahedron through post-stellation of an $\mathrm{M}_{12} \mathrm{~L}_{24}$ core. Nat. Chem. 4, 330-333 (2012).

4. Miras, H. N. et al. Unveiling the Transient Template in the Self-Assembly of a Molecular Oxide Nanowheel. Science 327, 7-74 (2010).

5. Kennedy, D. What Don't We Know? Scienc. 309, 75-75 (2005).

6. Service, R. F. How Far Can We Push Chemical Self-Assembly? Science 309, $95-95$ (2005).

7. Guo, L.-Y. et al. Core-Shell $\left\{\mathrm{Mn}_{7} \subset(\mathrm{Mn}, \mathrm{Cd})_{12}\right\}$ Assembled from Core $\left\{\mathrm{Mn}_{7}\right\}$ Disc. J. Am. Chem. Soc. 139, 14033-14036 (2017).

8. Deng, Y.-K. et al. Hierarchical Assembly of a $\left\{\mathrm{Mn}_{15}^{\mathrm{II}} \mathrm{Mn}_{4}^{\mathrm{III}}\right\}$ Brucite Disc: Step-by-Step Formation and Ferrimagnetism. J. Am. Chem. Soc. 138, 1328-1334 (2016).

9. Schröder, D. Applications of Electrospray Ionization Mass Spectrometry in Mechanistic Studies and Catalysis Research. Acc. Chem. Res. 45, 1521-1532 (2012)

10. Cook, T. R. \& Stang, P. J. Recent Developments in the Preparation and Chemistry of Metallacycles and Metallacages via Coordination. Chem. Rev. 115, 7001-7045 (2015).

11. Yu, G. C. et al. Antitumor Activity of a Unique Polymer That Incorporates a Fluorescent Self-Assembled Metallacycle. J. Am. Chem. Soc. 139, 15940-15949 (2017).

12. Zheng, H. et al. Assembly of a Wheel-Like $\mathrm{Eu}_{24} \mathrm{Ti}_{8}$ Cluster under the Guidance of High-Resolution Electrospray Ionization Mass Spectrometry. Angew. Chem. Int. Ed. 57, 10976-10979 (2018).

13. Wang, Q. M., Lin, Y. M. \& Liu, K. G.Role of Anions Associated with the Formation and Properties of Silver Clusters. Acc. Chem. Res. 48, 1570-1579 (2015)

14. Brown, C. J., Toste, F. D., Bergman, R. G. \& Raymond, K. N. Supramolecular Catalysis in Metal-Ligand Cluster Hosts. Chem. Rev. $115,3012-3035$ (2015)

15. Xu, F. et al. Correlating the magic numbers of inorganic nanomolecular assemblies with a $\left\{\mathrm{Pd}_{84}\right\}$ molecular-ring Rosetta Stone. Proc. Natl. Acad. Sci. USA 109, 11609-11612 (2012).

16. Kong, X. J., Long, L. S., Zheng, Z. P., Huang, R. B. \& Zheng, L. S. Keeping the Ball Rolling: Fullerene-like Molecular Clusters. Acc. Chem. Res. 43, 201-209 (2010).

17. Kaczmarek, M. T., Zabiszak, M., Nowak, M. \& Jastrzab, R. Lanthanides: Schiff base complexes, applications in cancer diagnosis, therapy, and antibacterial activity. Coord. Chem. Rev. 370, 42-54 (2018).

18. Zhang, J., Xu, L. \& Wong, W.-Y. Energy materials based on metal Schiff base complexes. Coord. Chem. Rev. 355, 180-198 (2018).

19. Meng, Q. et al. Mono- and dinucleating $\mathrm{Ni}(\mathrm{II}), \mathrm{Cu}(\mathrm{II}), \mathrm{Zn}(\mathrm{II})$ and $\mathrm{Fe}(\mathrm{III})$ complexes of symmetric and unsymmetric Schiff bases incorporating salicylimine functions-Synthetic and structural studies. Polyhedron 74, 113-121 (2014).

20. Gale, P. A. \& Caltagirone, C. Anion sensing by small molecules and molecular ensembles. Chem. Soc. Rev. 44, 4212-4227 (2015).

21. Lustig, W. P. et al. Metal-organic frameworks: functional luminescent and photonic materials for sensing applications. Chem. Soc. Rev. 46, 3242-3285 (2017).

22. Kelley, S. O. Advancing Ultrasensitive Molecular and Cellular Analysis Methods to Speed and Simplify the Diagnosis of Disease. Acc. Chem. Res. 50, 503-507 (2017). 
23. Zhao, S.-S., Yang, J., Liu, Y.-Y. \& Ma, J.-F. Fluorescent Aromatic Tag-Functionalized MOFs for Highly Selective Sensing of Metal Ions and Small Organic Molecules. Inorg. Chem. 55, 2261-2273 (2016).

24. Liu, J.-J. et al. Encapsulating Naphthalene in an Electron-Deficient MOF to Enhance Fluorescence for Organic Amines Sensing. Inorg. Chem. 55, 3680-3684 (2016).

25. Zeng, G. et al. 3d-4f Metal-Organic Framework with Dual Luminescent Centers That Efficiently Discriminates the Isomer and Homologues of Small Organic Molecules. Inorg. Chem. 55, 1089-1095 (2016).

26. Li, L. et al. Dynamic Entangled Framework Based on an Iridium-Organic Unit Showing Reversible Luminescence Turn-On Sensing. Inorg. Chem. 54, 8872-8874 (2015).

27. Zheng, H.-Y., Lian, X., Qin, S. \& Yan, B. Lanthanide hybrids of covalently-coordination cooperative post-functionalized metal-organic frameworks for luminescence tuning and highly-selectively sensing of tetrahydrofuran. Dalton. Trans. 47, 6210-6217 (2018).

28. Hermon, L. et al. Dichloromethane biodegradation in multi-contaminated groundwater: Insights from biomolecular and compound-specific isotope analyses. Water Res. 142, 217-226 (2018).

29. Wu, D. F. et al. A new family of dinuclear lanthanide complexes constructed from an 8 -hydroxyquinoline Schiff base and $\beta$-diketone: magnetic properties and near-infrared luminescence. Dalton Trans. 48, 1392-1403 (2019).

30. Qin, Y. et al. Enhanced energy barriers triggered by magnetic anisotropy modulation via tuning the functional groups on the bridging ligands in $\mathrm{Dy}_{2}$ single-molecule magnets. Dalton Trans. 47, 15197-15205 (2018).

31. Ghosh, S. et al. Experimental and theoretical exploration of magnetic exchange interactions and single-molecule magnetic behaviour of bis $\left(\eta^{1}: \eta^{2}: \mu_{2}\right.$-carboxylate) $\mathrm{Gd}^{\mathrm{III}}{ }_{2} / \mathrm{Dy}^{\mathrm{III}}{ }_{2}$ systems. Dalton Trans. 47, 11455-11469 (2018).

32. Bi, Y. et al. Thermostability and photoluminescence of Dy(III) single-molecule magnets under a magnetic field. Chem. Sci. 7, 5020-5031 (2016).

33. Zhang, P., Zhang, L., Lin, S. Y., Xue, S. \& Tang, J. Modulating Magnetic Dynamics of $\mathrm{Dy}_{2}$ System through the Coordination Geometry and Magnetic Interaction. Inorg. Chem. 52, 4587-4592 (2013).

34. Mazarakioti, E. C. et al. Large Energy Barrier and Magnetization Hysteresis at $5 \mathrm{~K}$ for a Symmetric $\left\{\mathrm{Dy}_{2}\right\}$ Complex with Spherical Tricapped Trigonal Prismatic Dy III Ions. Inorg. Chem. 56, 3568-3578 (2017).

35. Huo, Y. et al. Effect of Bridging Ligands on Magnetic Behavior in Dinuclear Dysprosium Cores Supported by Polyoxometalates. Inorg. Chem. 58, 1301-1308 (2019).

36. Sheldrick, G. M. Acta Crystallogr., Sect. C. Struct. Chem. 71, 3-8 (2015).

\section{Acknowledgements}

This work was supported by the National Natural Science Foundation of China (21601038 and 21771043) and the Guangxi Natural Science Foundation (2016GXNSFAA380085).

\section{Author Contributions}

The experiments were performed by Kai-Qiang Mo, Xiong-Feng Ma, and Hai-Ling Wang under the direction of Zhong-Hong Zhu, Yan-Cheng Liu, Hua-Hong Zou, and Fu-Pei Liang. All authors have given their approval to the final version of the manuscript.

\section{Additional Information}

Supplementary information accompanies this paper at https://doi.org/10.1038/s41598-019-48696-y.

Competing Interests: The authors declare no competing interests.

Publisher's note: Springer Nature remains neutral with regard to jurisdictional claims in published maps and institutional affiliations.

(c) (i) Open Access This article is licensed under a Creative Commons Attribution 4.0 International

License, which permits use, sharing, adaptation, distribution and reproduction in any medium or format, as long as you give appropriate credit to the original author(s) and the source, provide a link to the Creative Commons license, and indicate if changes were made. The images or other third party material in this article are included in the article's Creative Commons license, unless indicated otherwise in a credit line to the material. If material is not included in the article's Creative Commons license and your intended use is not permitted by statutory regulation or exceeds the permitted use, you will need to obtain permission directly from the copyright holder. To view a copy of this license, visit http://creativecommons.org/licenses/by/4.0/.

(C) The Author(s) 2019 